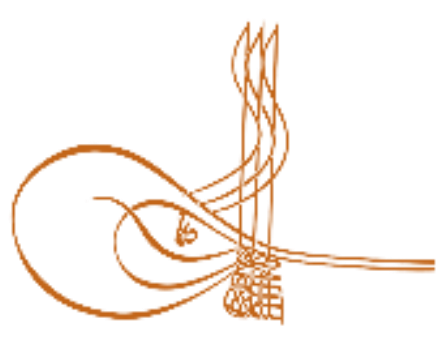

www.turkishstudies.net/social
Turkish Studies - Social Sciences

eISSN: $2667-5617$

Research Article / Araștırma Makalesi

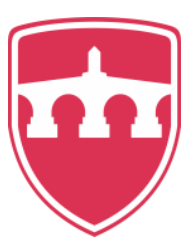

INTERNATIONAL

BALKAN

UNIVERSITY

Sponsored by IBU

\title{
Kariyer Uyum Yeteneklerinin X, Y ve Z Kuşakları Bakımından İncelenmesi: Bir Alan Araştırması
}

\author{
An Investigation of Career Adaptation Abilities by X, Y and Z Generations: A Field Survey
}

Ahmet Barış Solmaztürk* - Alper Gürer ${ }^{* *}$

\begin{abstract}
The concept of generation includes the characteristics that express the behavior and tendency of the individual throughout his/her life. In the studies conducted from past to present, it is seen that the change of generational characteristics is an interesting subject. In today's difficult working environment, career adaptation of employees is one of the conditions for their happiness in life. While it can be mentioned that there is generation conflict in the institutions where individuals from different generations work together, it can be said that increasing the studies aimed at determining career adaptation levels of generations will contribute to the explanability of the subject. In this context, under the framework of the field research which carried out in Turkey, individual career adaptability of 626 persons belonging to X, Y and Z generations measured. According to the findings, there were significant differences among the generations in the levels of anxiety and control which are dimensions of career adapt-abilities; the anxiety levels of the $\mathrm{Y}$ and $\mathrm{Z}$ generations were higher than the $\mathrm{X}$ generation; in terms of control level, it is determined that generation $\mathrm{Y}$ has more control level than $\mathrm{Z}$ generation. In addition, the differences in career adaptation skills according to other demographic characteristics was examined. According to this, while there was no significant difference according to gender, there were differences in anxiety and control levels according to education level. Anxiety levels were higher in people who have graduate education level compared to undergraduate level. In the control levels, it is significant that the control levels of those who have graduate education are higher than those who have undergraduate and associate education level. While the curiosity levels of the diplomaed people were higher than those who were continuing their education, it was determined that the anxiety levels of the students and those who doesn't work were higher than the diplomaed people and employees.
\end{abstract}

Structured Abstract: Career adaptation abilities, which are based on the concept of career maturity, which Super (1980) handles within the framework of life-long life area approach, are related to the mental and physical change of the person in the career development process. This change is faster especially at a young

${ }^{*}$ Dr.
Dr.
ORCiD 0000-0001-6181-5172
solmazturk@ gmail.com
${ }^{* * *}$ Dr. Öğr. Üyesi, Kırıkkale Üniversitesi, Keskin Meslek Yüksekokulu, Yönetim ve Organizasyon Bölümü.
Asst. Prof. Dr. Kirlkkale University, Keskin Vocational School, Department of Management and Organization.
ORCiD 0000-0002-6745-7895
alpergurer@ gmail.com
Cite as/ Atıf: Solmaztürk, A.B., Gürer, A. (2020). Kariyer uyum yeteneklerinin X, Y ve Z kuşakları bakımından
incelenmesi: bir alan araştırmas1, Turkish Studies - Social, $15(3)$,

incelenmesi: bir alan araştırmas1,
https://dx.doi.org/10.29228/TurkishStudies.40058

Received/Geliş: 08 December/Aralık 2019

Accepted/Kabul: 25 April/Nisan 2020

Copyright $($ INTAC LTD, Turkey 
age. The differentiation of opinions and thoughts about the career, the approach and interest in the opportunities that confront the individual, and the choices are made during life are realized within the framework of career adaptation abilities.

Individual can make a number of decisions that cause changes in existing career preferences and perspectives in order to ensure, maintain or improve career cohesion. The actions and decisions taken by individuals belonging to different age generations will be expected to take place within the framework of their age generation.

It will be a rather narrow approach in defining the concept of generation only with the age ranges of individuals. As emphasized in the resource studies, the age ranges used in determining the generations are related to the collection of personal characteristics specific to certain generations under certain age groups. On the other hand, these personal characteristics that define the generations reflect the characteristics of the period in which individuals live and are affected by this. As Parry and Urwin (2010: 91) stated, the concept of generation is also a concept that outweighs the sociological aspect. Therefore, it is not easy to making general and clear distinguishes between generations. Because the culture and life styles of individuals can vary according to countries, regions and even cities. For this reason, although they have close values, it is seen that there are different age ranges attributed to generations in different sources.

It is seen that individuals belonging to the same generation have similar behavioral and personal characteristics. In other words, it can be said that individuals belonging to different generations have different behavioral and personal characteristics. There has been an increase in the subject of these differences, especially recently. The aim of this study is to investigate the relationship between the generations of individuals and their career adaptation abilities. In addition, it is aimed to examine career adaptation abilities in terms of control variables such as gender, educational status, graduation status, and employment status. In this study, besides $\mathrm{X}$ and $\mathrm{Y}$ generations, the generation $\mathrm{Z}$, which has started its transition to business life, has been examined.

In this context, the following hypotheses have been tested.

$\mathrm{H}_{1}$ : There is a significant difference in career adaptation ability levels with respect to generation.

$\mathrm{H}_{2}$ : There is a significant difference in career adaptation ability levels with respect to gender.

$\mathrm{H}_{3}$ : There is a significant difference in career adaptation ability levels with respect to education

level.

$\mathrm{H}_{4}$ : There is a significant difference in career adaptation ability levels with respect to graduation status.

$\mathrm{H}_{5}$ : There is a significant difference in career adaptation ability levels with respect to employment status.

Questionnaire method was used to collect research data. The questionnaire consisting of two parts is listed as the first part where demographic information is gathered and the second part with statements about career adaptation abilities. The constructed questionnaire was distributed both in writing and online.

McCrindle's (2014: 5-6) study was based on for the age range used to define generations. In measuring the career adaptation abilities, the questionnaire of the International Career Adaptation-Ability Scale developed by Savickas and Profeli (2012) was used. This measurement tool was adapted to Turkish by Kanten (2012). The relevant measurement tool consists of 24 questions and includes 4 sub-dimensions. These dimensions are anxiety, control, curiosity and trust.

In Turkey, $\mathrm{X}, \mathrm{Y}$ and $\mathrm{Z}$ generations are the individuals involved in the research universe. Within this scope, individuals who are continuing or graduating from high school, associate, undergraduate and graduate education throughout the country and who are currently working or not working in a workplace are targeted. It was ensured to reach the target audience via either online communication channels like social media, email etc. or printed questionnaire forms. The data were collected through convenience sampling in May and June 2019 and 626 people were reached.

According to the research findings, the anxiety dimension levels of the $\mathrm{Y}$ and $\mathrm{Z}$ generations are higher than the $\mathrm{X}$ generation. As the individual matures and gains experience in dealing with problems;

Turkish Studies - Social, 15(3) 
career preferences, their roles in the job and family are stabilized, their future concerns and uncertainties are reduced. The belief that the generation $\mathrm{X}$ is content and his belief in authority is also thought to be effective in differentiating anxiety levels. In addition, the control size levels of the $\mathrm{X}$ and $\mathrm{Y}$ generations are higher than the $\mathrm{Z}$ generation. It is possible to retain control in hand due to high motivation, social sensitivity and anxious structure of $\mathrm{X}$ generation and personality trait of $\mathrm{Y}$ Generation. Generation Z, on the other hand, may prefer to cooperate in solving problems or making sense of something. It is believed that this explains the reason for the lower levels of control associated with his career.

As the research findings indicate, career adaptability levels do not differ significantly between men and women. It is possible to say that a common and false belief in terms of gender discrimination is also refuted in terms of career adaptability. In addition, it was found that those at the graduate level were more anxious than those at the undergraduate level. The desire to continue his education will enable him to question his current status and raise his career prospect. This will increase the level of anxiety in terms of career adaptability. From an opposite perspective, the level of future anxiety of the individual who is satisfied with the educational situation will probably be lower. In addition, it was found that anxiety levels of those who continued their education were higher than those of graduates. It can be said that continuing education brings professional uncertainty and anxiety. On the other hand, it was determined that the level of curiosity and control of graduates from the other was high. Acceleration of graduate individuals' job-related searches will also increase their desire to take control. It is thought that gaining new experiences in this process has increased the level of curiosity. In addition, it was found that anxiety levels of those who did not work in a job were higher than those of employees. Not working will cause anxiety about the future of the individual. Because an individual who has a job has a certain guarantee; they have the chance to consolidate its current position, get to know themselves and reduce anxiety in this direction with the gained experience. Anxiety levels will decrease as the individual gets to know himself/herself and gets a choice chance.

Keywords: Management and Organization, Career Adaptation Abilities, Generation X, Generation Y, Generation Z

Öz: Kuşak kavramı, bireyin yaşamı boyunca davranış tarzını ve eğilimini ifade eden özellikleri içinde barındırmaktadır. Geçmişten günümüze yapılan çalışmalarda kuşaksal özelliklerin değişiminin ilgi çeken bir konu olduğu görülmektedir. Günümüz çetin çalışma ortamı içerisinde çalışanların kariyer uyumu ise yaşamdan mutlu olmalarının koşullarından biridir. Farklı kuşaktan bireylerin bir arada çalıştı̆g kurumlarda kuşak çatışmasının varlığından söz edilebilecekken genel anlamda kuşakların kariyer uyum yeteneklerinin belirlenmesini amaçlayan çalışmaların artmasının konunun açıklanabilirliğine katkı sağlayacağı söylenebilir. Bu bağlamda Türkiye genelinde gerçekleştirilen alan araştırması çerçevesinde $X, Y$ ve $Z$ kuşağına mensup 626 bireyin kariyer uyum yetenekleri ölçülmüştür. Elde edilen bulgulara göre kariyer uyum yetenekleri alt boyutlarından kaygı ve kontrol düzeylerinde kuşaklar arasında belirgin farklılıklar olduğu; $Y$ ve $Z$ kuşaklarının kaygı düzeylerinin $\mathrm{X}$ kuşağına göre daha yüksek olduğu; kontrol düzeyi açısından ise $\mathrm{Y}$ kuşağının Z kuşağına göre daha fazla kontrol düzeyine sahip olduğu tespit edilmiştir. Ayrıca araştırmada kariyer uyum yeteneklerinin diğer demografik özelliklere göre değişimi de incelenmiştir. Buna göre cinsiyet açısından anlamlı bir fark bulunmazken eğitim düzeyine göre kaygı ve kontrol düzeylerinde farklılıklar tespit edilmiştir. Kaygı düzeyleri lisansüstü eğitim alanlarda lisans düzeyine göre yüksek çıkmıştır. Kontrol düzeylerinde ise yine yüksek lisans eğitimi alanların kontrol düzeylerinin önlisans ve lisans mezunlarına göre yüksek çıkması anlamlıdır. Mezunların merak düzeyleri eğitimlerine devam etmekte olanlara göre yüksek çıkarken öğrencilerin ve bir işte çalışmayanların kaygı düzeylerinin mezunlara ve çalışanlara göre fazla olduğu tespit edilmiştir.

Anahtar Kelimeler: Yönetim ve Organizasyon, Kariyer Uyum Yetenekleri, X Kuşağı, Y Kuşağı, Z Kuşağı.

\section{Giriş}

Kuşak teorisinin vurguladığı gibi bireyin ileride şekillenecek davranış ve karar alma kalıpları, içinde büyüdüğü zaman, toplumsal ortam ve diğer değişkenlerden etkilenmektedir. Kuşaklar arasındaki farklılığın temel nedenlerinden olan bu durum aynı zamanda insanın içinde bulunduğu koşullara uyum sağlama yetisinin de bir göstergesidir. Değişen dış çevre ve yaşam 
koşulları bireyin bu koşullara göre değişmesini sağlamakta bu durum da farklı davranış varyasyonlarının türemesi ile kuşaklar arası farklılıkları oluşturmaktadır. Bununla birlikte toplumsal değişimin dinamikleri de yine insanlar tarafından sağlanmaktadır. Bu bağlamda kuşakların değişimi ile ilgili çalışmalar insanlığın toplum içerisindeki hem dönüştürücü hem de bundan etkilenen yapısını ortaya koyması bakımından da önemlidir.

Kuşak farklı1ıkları aynı zamanda çalışma ortamı açısından da önemli bir unsurdur. Özellikle Y kuşağının ardından Z kuşağının da iş yaşamına girecek yaş aralığına gelmesi ile birlikte kurum içerisinde gerek farklılıkların yönetilmesinde, gerekse çatışmaların kontrolü, kuşaklar arasındaki bu çatışmaların birer firsata çevrilebilmesi ve insan kaynaklarının planlanması vb. pek çok konuda farklı çözümlere ihtiyaç duyulacaktır. Bu konuda çalışmalara ağırlık veren ve öncülük eden kurumlar bu çeşitlilik ve değişimden gerek yaratıcılık gerekse yenilik yapma yönünden fayda sağlayacaklardır.

\section{Kariyer Uyum Yetenekleri}

Bireylerin çalışma hayatları boyunca deneyimledikleri herşey kariyer kavramının içerisine dâhil edilebilir (Noe, 2009: 400). Kariyer, "Carrus" Latince kökünden türemiş at arabası anlamında, "carrera" kökünden türemiş bir başka terim ise yol anlamında kullanılmıştır (Ertürk, 2011: 200). Dündar (2013: 307)'1n belirttiği gibi kariyer, kişinin sahip olduğu yeteneklerini ve becerilerini kullanarak mesleğinde ilerlemesi anlamına gelmektedir. Öte yandan kişinin istekleri, beklentileri ve işine karşı duyduğu motivayon da bu ilerleyişe yön vermektedir.

Kariyer uyum yetenekleri kavramsal gelişimi itibariyle Super (1980)'in yaşam boyu yaşam alanı yaklaşımı çerçevesinde ele aldığı kariyer olgunluğu kavramına dayandırılmaktadır. Dolayısı ile kavramın ana çıkış noktası kişinin kariyer gelişimi süreci içerisindeki zihinsel ve fiziksel değişimi ile ilişkilidir. $\mathrm{Bu}$ değişim özellikle genç yaşlarda daha hızlı olmaktadır. Kariyer konusundaki görüş ve düşüncelerin farklılaşması, bireyin karşısına çıkan firsatlara olan yaklaşımı ve ilgisi ile yaşamı boyunca yaptığı seçimler kariyer uyum yetenekleri çerçevesinde gerçekleşmektedir.

Kariyer uyum yetenekleri kavramı ilk olarak Super ve Knasel (1981) tarafindan kullanılmıştır (Savickas, 1994). Kavramın gelişmesinde ise özellikle Savickas (1997)'ın çalışmaları katkı sağlamıştır. Kariyer uyum yetenekleri kişinin hem iş ile ilgili beklenen ve beklenmedik değişimlere karşı durabilmesi hem de üstlenmesi gereken yeni roller için uyum sağlayabilmesidir (Erdoğmuş Zorver ve Korkut Owen, 2014: 316). Savickas (1997: 254)'1n tanımlaması ile kariyer uyumu, çalışanın işindeki konumuna uygun davranışları sergilemesi, görevinin gerekleri için hazırlık yapması, işi ile ilgili olarak beklenmedik durumlar ve değişimler karşısında kayıtsız kalmaması bunlarla ilgilenme konusunda istekli olmasıdır. Kariyer uyum yeteneği kavramı kişinin kariyeri ile uyumlu olmasını sağlayan bir takım özellikleri ile ilgilenmektedir. Diğer bir ifade ile kariyer uyum yetenekleri kişinin o kariyeri neden seçtiğiyle ilgilenir. Buradan hareketle kariyer uyum yeteneği aslen bir süreci de ifade eder ve bireyin mevcut kariyerinde veya kariyer öncesi döneminde sosyal hayata katılımını mümkün kılan kişilik özelliklerinin keşfedilmesidir (Savickas vd., 2009: 244). Bu süreç, kişinin yaşamı boyunca belirli bir farkındalık düzeyine erişmesine, kendisini ve çevresini keşfetmesine olanak tanır. Savickas ve Porfeli (2012) tarafından belirtildiği üzere şu safhalardan meydana gelmektedir:

- Bireysel keşif safhası, kişinin yeteneklerini ve ilgi duyduğu alanları tespit ederek kendini tanımaya başladığı safhadır.

- Çevresel keşif, dış ortamda hali hazırda bulunan rollerin keşfedilmesi ve kendi yetenekleri ve hedefleri ile karşılaştırması safhasıdır.

- Planlama ve karar safhası, kişinin ilk iki safhada elde ettiği bilgiler doğrultusunda kariyerine yönelik olarak planlar yapması ve bir karar aşamasına gelme safhasıdır. 
Kişinin kariyer yönelimi veya algısı dinamik bir yapıdadır. Bu bağlamda kişi mevcut kariyerinde ilerlemek için bu yapıya uyum sağlamalıdır. Kariyer uyumunun sağlanması kişiye atfedilen bir yetenektir. Yousefi vd. (2011: 264)'nin vurguladığ 1 gibi kariyer uyum yetenekleri, özellikle kariyer tercihleri henüz belirli bir kalıba girmemiş olan genç çalışanların gerek çalıştıkları işe gerekse iş yaşamının dinamiklerine uyum sağlamalarına yönelik gösterdikleri performansı içermektedir.

Savickas ve Porfeli (2012: 663), kariyer uyum yeteneklerinin ortaya çık1ş gücünü dört kaynağa bağlamaktadır. İngilizce baş harfleri nedeniyle 4c olarak da belirtilen bu kaynaklar kayg1 (concern), kontrol (control), merak (curiosity) ve güven (confidence) şeklinde sıralanabilir:

- Kaygı, kişinin gelecek kaygısıdır. İleride ne gibi durumlar ile karşılaşacağına dair mevcut olan belirsizlik için kaygılanma ve ilerisi için hazırlanma isteğini de beraberinde getirir.

- Kontrol, kişi kendini geliştirmekten sorumludur. Azim, 1srar ve iç disiplin ile kendi çevrelerini şekillendirir.

- Merak, kişi deneyimlediği olaylar çerçevesinde kendisini hangi rolde ve yerde görmek istediği ile ilgili bir araştırma isteği duyacaktır.

- Güven, kişinin kazandıği deneyim ve edindiği bilgi doğrultusunda neleri başarabileceği konusunda kendisinde bir güven oluşmaktadır.

Kişi, kariyer uyumunu sağlamak, onu korumak veya geliştirmek amacıyla bir takım kararlar alabilir. $\mathrm{Bu}$ kararları çerçevesinde mevcut kariyer tercihlerinde ve bakış açılarında değişikliklerin olması mümkündür. Kariyer uyum yetenekleri açısından farklı kuşaklarda yer alan bireylerin kariyeri ile ilgili gerçekleştirdikleri eylemlerin ve aldıkları kararların kendi kuşak özellikleri çerçevesinde gerçekleşeceği ve bu bağlamda bir farklılık oluşturacağı düşünülmektedir.

\section{Kuşak Kavramı}

Kuşak kavramı en yalın tanımı ile "yaklaşık olarak aynı yıllarda doğmuş, aynı çağın şartlarını, dolayısıyla birbirine benzer sıkıntıları, kaderleri paylaşmış, benzer ödevlerle yükümlü olmuş kişilerin topluluğu" (TDK Sözlük, t.y.) olarak tanımlanabilir. Dolayısı ile kuşakların oluşması bir takım benzer özelliklerin yanı sıra kişilerin yaşamlarını sürdürdükleri zaman kesiti ve toplumsal düzende yarattıkları değişim ile de ilgilidir.

Keleş (2011: 129)'in vurguladığı gibi kuşaklar arasında kişilik özelliklerinin yanı sıra çalışma hayatına olan bakış açıları bakımından da farklılıklar bulunmaktadır. Bu durum doğanın değişime olan bağlılığı ile ilgilidir. Tıpkı mevsimlerin, çevrenin, değişimi gibi kuşaksal özelliklerin de değişimi kaçınılmazdır. Kuşaklar arsındaki bu farklılıkların incelendiği çalışmalar ve bu bağlamda bireylerin kuşaksal bakımdan sınıflandırılması 1920'li yıllara kadar uzanmaktadır. Alman Sosyolog Karl Mannheim'ın çalışmalarının kuşaksal sınıflandırma konusunda öncü olduğu belirtilmektedir (Taylor, 2008'den akt. Arslan ve Staub, 2015: 5). Öte yandan kavramın teorik çerçevede ele alınmasında ise Abramson ve Inglehart (1992) ile Howe ve Stratuss (1991, 1992)'un çalışmaları ilk olarak kabul edilmektedir. Bu teoriye göre tarihsel süreçteki olaylar o dönemin benzer nesil özellikleri ile ilişkilendirilmektedir. Dolayısı ile her nesil veya kuşak yaşam sürdüğü dönemin sosyolojik, ekonomik ve politik bakış açılarını oluşturmaktadır. Belirli benzer özellikteki kişilerin birer kuşak olarak adlandırıldığı bu zaman aralıkları teoride "turning" veya "döngü" olarak tanımlanmaktadır. Her bir dönüş 20-22 yıl sürmekte ve insan yaşamını kapsayan 80-90 yıllık büyük bir döngünün parçasını oluşturmaktadır.

Kaynak çalışmaların vurguladığı gibi kuşakların tanımlanmasının ana unsurunu kuşakların yaş aralığından ziyade onların sahip oldukları kişisel özellikler, yetişme koşulları ve kişilikleri oluştururken tüm bunlar içinde bulundukları dönemin özelliklerini yansıtmaktadır. Parry ve Urwin (2010: 91)'in belirttiği gibi kuşak kavramı sosyolojik yönü ağır basan bir kavramdır. Dolayısı ile genel geçer ve net bir kuşaklar arası ayrım yapılması kolay değildir. Çünkü bireylerin kültür ve 
yaşayış biçimleri ülkelere, bölgelere ve hatta şehirlere göre dahi değişiklik gösterebilmektedir. $\mathrm{Bu}$ sebeple birbirine yakın değerlere sahip olsalar da farklı kaynaklarda kuşaklara atfedilen farklı yaş aralıkları olduğu görülmektedir. Bu çalışmada kuşakların tanımlanmasında kullanılan yaş aralığı için McCrindle (2014: 5-6)'ın çalışması esas alınmıştır.

X Kuşağı, 1960'lı yılların ortaları ile 1970'li yılların sonları arasında dağanları kapsamaktadır. "Bebek Patlaması" kuşağının ardından gelmeleri sebebiyle bu kuşak ile de benzeşen yönleri bulunmaktadır (Demirkaya vd., 2015: 189; Ekşili vd., 2014: 2; Hicks ve Hicks, 1999; Zemke vd., 2013). X kuşağı ile ilgili tanımlarda genel olarak yazında Coupland'ın çalışmalarına atıf verilmektedir. Buna göre $X$ kuşağ 1 toplum içerisinde aykırı ve sert politik görüşleri ile ayrılmaktadır. Giyim kuşam ve müzik zevkleri açısından da farklı olan X kuşağ toplum içinde statü elde etme, variyet kazanma, daha fazla sosyal davranışlar sergileme yönünde eğilimlere sahiptir (Coupland, 1989: 83).

Y Kuşağının kapsamı 1980’li yıllar ile başlayıp 1990‘ların ortasına kadar uzanmaktadır. Broadbridge vd. (2007)'nin vurguladığ gibi milenyum kuşağ 1 , internet kuşağ 1 vb. şekilde adlandırılmaktadır. Bu kuşağın özellikleri dikate alındığında kendinden önce gelen X kuşağından farklı özelilikler barındırdığı söylenebilir. Diğer bir ifade ile Y kuşağını var eden özellikler içerisinde X kuşağından farklı oluşları da yer almaktadır. Senbir (2004: 25) ve Konakay vd. (2015: 216)'nin çalışmalarında belirtikleri gibi bilgisayarlar, cep telefonları vb. araçların gelişim gösterdiği bir dönemde doğan Y kuşağı mensubu bireylerin teknoloji ile araları iyidir. Yeni Dünya düzeninin gereklerine uygun olarak rahat ve bireysel yapıları ön plandadır. Diğer bir ifade ile yetiştikleri toplumun özelliklerinin kişileri tüketime yönlendirmesiyle anne ve babalarının yetiştikleri dönemden farklıdır (Aminul vd., 2011: 1803). Bu farklılaşma iş yaşamına olan bakış açılarını da farklılaştırmaktadır. Keleş (2011: 138) 'in belirttiği gibi Y kuşağı iş ortamında takdir beklentisi içinde olmaktadır. Buna bağlı olarak sürekli yenilik yapma yeni bir şeyler üretme isteği içindedir.

Z Kuşağı, 1995-2009 yılları arasında doğan kişileri kapsamaktadır. Taş vd. (2017: 1033)'nin belirttiği gibi önceki kuşaklardan farklı olarak teknoloji düzeyinin diğer kuşakların dönemlerine nazaran daha yüksek olduğu dönemde doğmuşlardır. Dolayısı ile internet ile doğdukları anda tanışmışlardır. Sosyal medya ve diğer dijital uyarıcıların çevrelediği toplumsal ortam içerisinde bu yeteneklerinin gelişmesi kaçınılmazdır. El becerisi, görme, duyma vb. becerilerinin gözle görülür şekilde gelişmiş olduğundan söz edilebilir (Berkup, 2014: 224). Bebek patlaması kuşağının yaşam döngüsü çerçevesinde yavaş yavaş çalışma hayatından çekilmesi doğrultusunda $\mathrm{Z}$ kuşağı da iş yaşamı safhasına tam olarak geçecektir (Hutchings ve Michailova, 2014: 112).

Tablo 1: Kuşakların Özellikleri

\begin{tabular}{lll}
\hline X Kuşağı & Y Kuşağı & Z Kuşağı \\
\hline Sadakat duyguları değişken & Sadakat duyguları az & İşbirlikçi \\
Otoriteye saygılı & Otoriteyi zor kabullenen & Yaratıcı \\
Topluma duyarlı & Bağımsızlı̆ı̆ına düşün & Teknoloji içine doğan \\
İş motivasyonu yüksek & Çok sık İş değiştiren & \\
Kanaatkâr & Bireyci & \\
Kaygılı & Teknolojiyle büyüyen & \\
Teknolojiyle ilişkisi düşük & & \\
\hline \multicolumn{2}{l}{ Kaynak: Deneçli ve Deneçli, 2010'dan akt. Taș vd., 2017: 1038. }
\end{tabular}

\section{Kuşaklar Arasında Kariyer Uyum Yeteneklerinin İncelenmesi}

Bu kısımda araştırmanın amacı, yöntemi, evreni ve örneklemi, modeli ve hipotezleri ile araştırma bulgularına yer verilmiştir. 


\section{Amaç}

Aynı kuşağa mensup olan bireylerin benzer davranışsal ve kişisel özelliklere sahip oldukları görülmektedir. Diğer bir ifade ile farklı kuşaklara mensup olan bireylerin farkl1 davranışsal ve kişisel özellikler taşıdığı söylenebilir. Bu farklılıklarının özellikle son zamanlarda inceleme konusu edilmesinde bir artış söz konusudur. Bu çalışmanın amacı, bireylerin mensubu bulundukları kuşaklar ile kariyer uyum yetenekleri arasındaki ilişkinin araştırılmasıdır. Bu çalışmada katılımcıların kariyerlerine bakış açısı ve uyum sağlama düzeyleri kaygı, kontrol, merak ve güven alt boyutları bağlamında genel olarak kabul gören $\mathrm{X}$, $\mathrm{Y}$ ve $\mathrm{Z}$ kuşaklar sınıflandırmasına ve bir takım demografik özelliklere göre incelenmiştir.

\section{Yöntem ve Ölçüm Aracı}

Alan araştırmasında verilerin toplanmasında anket yöntemi tercih edilmiştir. Bu bağlamda hem elektronik ortamda hem de basılı olarak kullanılmak üzere soru formu hazırlanmıştır. Anket formunun ilk kısmında katılımcıların mensubu bulundukları kuşağın belirlenmesi ve diğer demografik özelliklerin tespit edilmesine yönelik sorular yer almaktadır. Bu sorular sırasılya cinsiyet, doğum yılı aralığı, eğitim durumu, mezuniyet durumu ve çalışma durumu şeklindedir. İkinci kısımda ise katılımcıların kariyer uyum yeteneklerini belirlemeye yönelik soru formu yer almaktadır. Kariyer uyum yeteneklerinin ölçülmesinde Savickas ve Profeli (2012) tarafından geliştirilen Uluslararası Kariyer Uyum-Yetenekleri Ölçeği'ne ait soru formundan faydalanılmıştır. Bu ölçüm aracı Kanten (2012) tarafindan Türkçe'ye uyarlanmıştır. İlgili ölçüm aracı 24 sorudan oluşmakta ve 4 alt boyutu içermektedir. Bu boyutlar kaygı, kontrol, merak ve güven şeklindedir.

Toplanan verilerin analiz edilmesinde SPSS programında faydalanılmıştır. Ölçüm aracının güvenilirlik geçerlilik analizleri için temel bileşenler faktör analizi uygulanmıştır. Güvenilirlik analizi için Cronbach Alpha değeri incelenmiştir. Ölçüm değişkeninin demografik özelliklere göre farklılaşma durumu Kruskal Wallis ve Mann Whitney-U testleri ile incelenmiştir.

\section{Evren ve Örneklem}

Bu çalışma genel olarak Türkiye'deki $X, Y$ ve $Z$ kuşağına dâhil olan bireyleri evren kapsamı olarak ele almaktadır. Bu kapsam dâhilinde ülke çapında lise, önlisans, lisans ve lisansüstü eğitimlerini sürdüren veya mezun olan ve hali hazırda bir iş yerinde çalışan veya çalışmayan bireyler hedeflenerek gerek sosyal medya, e-posta vb. çevrimiçi iletişim kanallarından gerekse basılı anket formları aracılığı ile hedef kitleye ulaşılması sağlanmıştır. Veriler 2019 yılı Mayıs ve Haziran ayları içerisinde kolayda örnekleme yoluyla toplanmış ve 626 kişiye ulaşılmıştır. Bu değer Yazıcıoğlu ve Erdoğan (2004: 50) tarafından belirtildiği gibi \%95 güven aralığında ve sosyal bilimlerde genel olarak kabul edilen p ve q aralığında yeterli bir örneklem büyüklüğüdür.

Tablo 2: Demografik Özelliklerle İlgili Tanımlayıcı İstatistikler

\begin{tabular}{lllcc}
\hline Gruplar & Alt Gruplar & f & \% \\
\hline Cinsiyet & Erkek & & 258 & 41,21 \\
& Kadın & & 368 & 58,79 \\
\hline Yaş Aralığı & $1965-1979$ & (X Kuşă̆ı) & 196 & 31,31 \\
& $1980-1994$ & (Y Kuşağı) & 234 & 37,38 \\
& 1995-2009 & (Z Kuşağı) & 196 & 31,31 \\
\hline Eğitim Durumu & Lise & & 39 & 6,23 \\
& Önlisans & 171 & 27,32 \\
& Lisans & 284 & 45,37 \\
& Lisansüstü & 132 & 21,09 \\
\hline Mezuniyet Durumu & Hayır & 196 & 31,16 \\
& Evet & 430 & 68,84 \\
\hline Çalışma Durumu & Hayır & & 215 & 34,35 \\
& Evet & 411 & 65,65 \\
\hline
\end{tabular}

www.turkishstudies.net/social 
Örnekleme ait demografik özelliklere Tablo 2'de yer verilmiştir. Bu bağlamda örneklemin $\% 41,21$ 'i erkek ve \%58,79'u kadındır. Eğitim durumu açısından dağılımın lisans düzeyinde yoğunlaştığ $(\% 45,37)$ görülürken mezunların oranı $\% 68,84$ ve hali hazırda bir işte çalışanların oranı ise \%65,65'dir. Alan araştırmasının esasını oluşturan kuşaklar arası dağılım ise X kuşağ $\% 31,31$, Y kuşağ $1 \% 37,38$ ve Z kuşağ $\% 31,31$ düzeyindedir.

\section{Araştırma Modeli ve Hipotezleri}

Kariyer uyum yeteneklerinin bireyin mensubu olduğu kuşak da dâhil olmak üzere cinsiyet, eğitim durumu, mezuniyet durumu ve bir işte çalışıyor olma durumu çerçevesinde farklılık gösterip göstermediği araştırmanın temel problemini teşkil etmekte olup; araştırma modeli ve hipotezleri aşağıdaki gibi oluşturulmuştur.

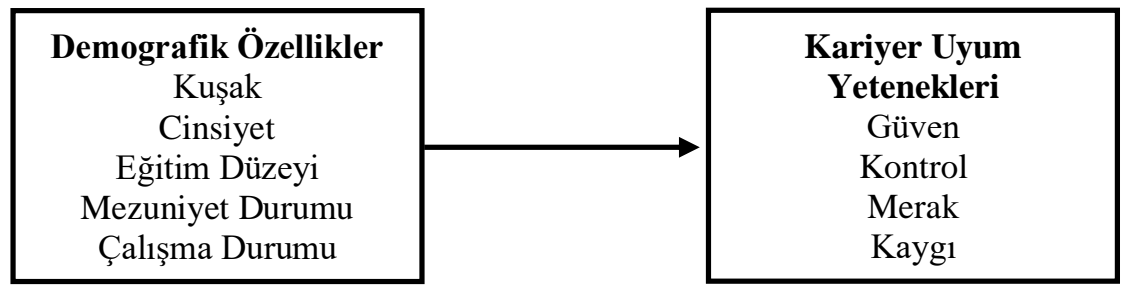

Şekil 1: Araştırmanın Modeli

$\mathrm{H}_{1}$ : Kariyer uyum yetenekleri düzeylerinde kuşağa göre anlamlı farklılık bulunmaktadır.

$\mathrm{H}_{2}$ : Kariyer uyum yetenekleri düzeylerinde cinsiyete göre anlamlı farkl11ık bulunmaktadır.

$\mathrm{H}_{3}$ : Kariyer uyum yetenekleri düzeylerinde eğitim düzeyine göre anlamlı farklılık bulunmaktadır.

$\mathrm{H}_{4}$ : Kariyer uyum yetenekleri düzeylerinde mezuniyet durumuna göre anlamlı farkl11ık bulunmaktadır. bulunmaktadır

$\mathrm{H}_{5}$ : Kariyer uyum yetenekleri düzeylerinde çalışma durumuna göre anlamlı farklılık 
Tablo 3: Kariyer Uyum Yetenekleri Faktör Yapısı

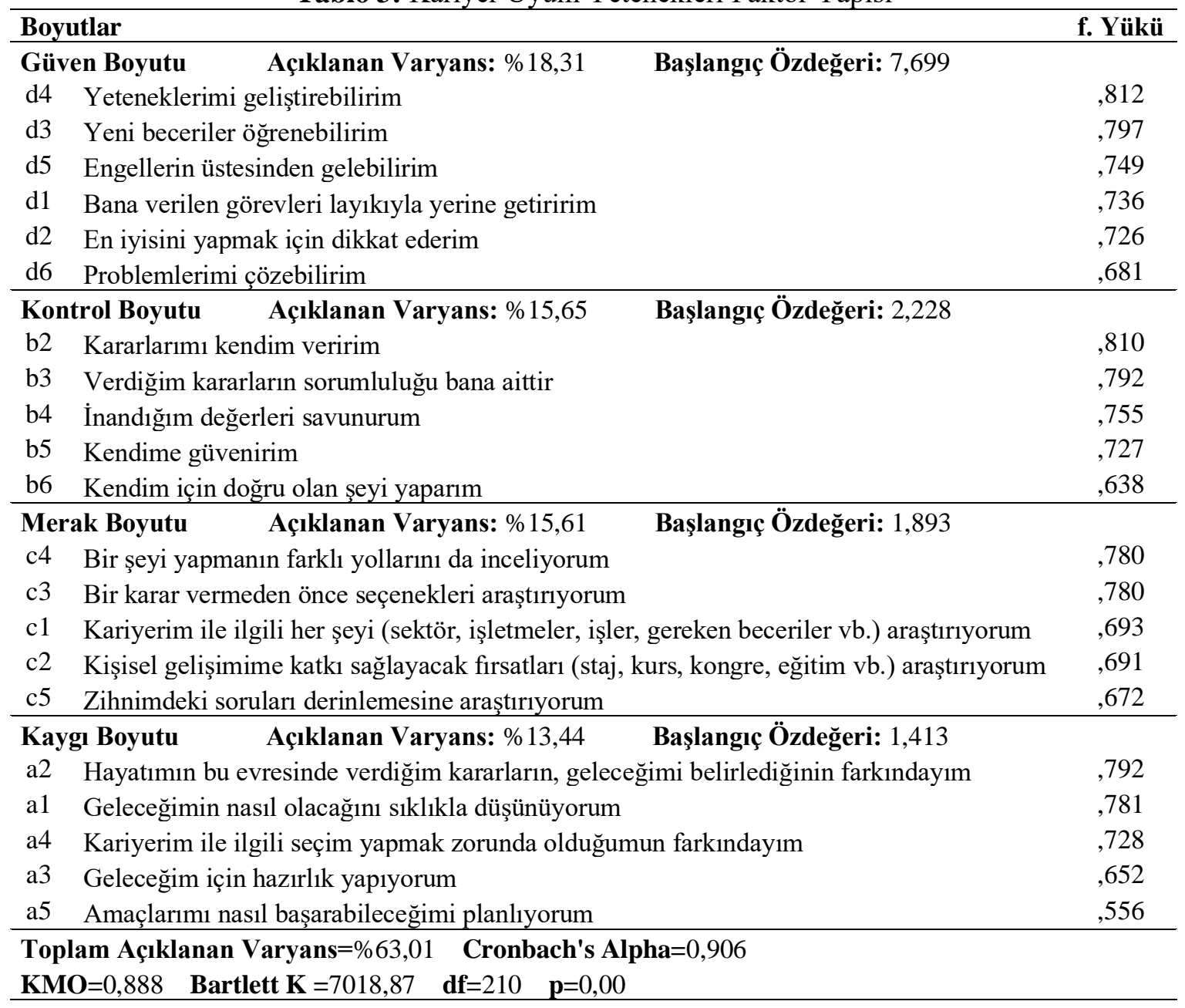

Kullanılan ölçüm aracı için temel bileşenler faktör analizi uygulanmıştır. Özdeğeri 1'den büyük olan 4 faktör yapısı oluşmuştur. Tablo 3'de yer aldığı üzere toplam açıklanan varyans \%63,01'dir. Cronbach's Alpha değeri $(0,906)$ yapılan ölçümlerin yüksek güvenilirlikte olduğunu göstermektedir. Orijinal çalışmadaki faktör yapısı beklendiği şekilde elde edilmiştir. Bu doğrultuda kayg1, merak ve kontrol boyutlarından birer adet olmak üzere toplamda üç adet ifade düşük faktör yükleri ve farklı boyutlarda yer almaları nedeniyle analiz dışında bırakılmıştır.

Tablo 4: Faktör ve Ölçek Ortalamaları

\begin{tabular}{lccccc}
\hline & $\mathbf{N}$ & Ortalama & Std. Sapma & Çarpıklık & Basıklık \\
\hline Güven & 626 & 4,47 &, 543 & $-0,890$ & 0,403 \\
\hline Kontrol & 626 & 4,33 &, 672 & $-1,407$ & 2,709 \\
\hline Merak & 626 & 3,97 &, 733 & $-0,876$ & 1,149 \\
\hline Kayg1 & 626 & 4,04 &, 779 & $-1,090$ & 1,397 \\
\hline Toplam & 626 & 4,20 &, 522 & $-0,786$ & 0,874 \\
\hline Kolmagorov-Smirnov ve Shapiro Wilk testlerinin anlamll1ık değerleri 0,05'den küçuktür.
\end{tabular}

Kariyer uyum yetenekleri alt boyutlarına ait ölçek ortalamalarına Tablo 4'de yer verilmiştir. Buna göre genel olarak katılımcıların güven düzeylerinin diğer boyutlarla karşılaştırıldığında görece daha yüksek düzeyde olduğu görülmektedir. Veriler normal dağılım göstermediği için parametrik olmayan testlerin kullanılmasına karar verilmiştir. 
Tablo 5: Kariyer Uyum Yetenekleri Düzeylerinin Kuşaklar Arasındaki Değişimi

\begin{tabular}{|c|c|c|c|c|c|c|}
\hline & & $\mathbf{N}$ & $\begin{array}{c}\text { Siralar } \\
\text { Ortalaması }\end{array}$ & $k^{2}$ & $\mathbf{P}$ & $\begin{array}{c}\text { Anlamlı } \\
\text { Fark }\end{array}$ \\
\hline \multirow{3}{*}{ Güven } & X kuşağ1 & 196 & 299,12 & \multirow{3}{*}{3,004} & \multirow{3}{*}{0,22} & \\
\hline & Y kuşağı & 234 & 328,30 & & & \\
\hline & Z kuşağ1 & 196 & 310,21 & & & \\
\hline \multirow{3}{*}{ Kontrol } & X kuşağ 1 & 196 & 321,56 & \multirow{3}{*}{10,376} & \multirow{3}{*}{$\mathbf{0 , 0 1}$} & $X>Z$ \\
\hline & Y kuşağı & 234 & 334,51 & & & $Y>Z$ \\
\hline & Z kuşağ1 & 196 & 280,36 & & & \\
\hline \multirow{3}{*}{ Merak } & X kuşağı & 196 & 314,96 & \multirow{3}{*}{3,198} & \multirow{3}{*}{0,20} & \\
\hline & Y kuşağı & 234 & 326,99 & & & \\
\hline & Z kuşağ & 196 & 295,93 & & & \\
\hline \multirow{3}{*}{ Kayg1 } & X kuşağ1 & 196 & 275,72 & \multirow{3}{*}{12,788} & \multirow{3}{*}{$\mathbf{0 , 0 0}$} & $Y>X$ \\
\hline & Y kuşağı & 234 & 327,02 & & & $Z>X$ \\
\hline & Z kuşağ & 196 & 335,14 & & & \\
\hline \multirow{3}{*}{ Toplam } & X kuşağ 1 & 196 & 301,93 & \multirow{3}{*}{5,167} & \multirow{3}{*}{0,08} & \\
\hline & Y kuşağı & 234 & 334,74 & & & \\
\hline & $Z$ kuşağ1 & 196 & 299,72 & & & \\
\hline
\end{tabular}

Kariyer uyum yetenekleri düzeylerinin kuşaklara göre değişimi Kruskal Wallis yöntemi kullanılarak incelenmiştir. Buna göre kaygı ve kontrol alt boyutlarında kuşak gruplarının ortalama düzeyleri arasındaki farklılık anlamlıdır $(\mathrm{p}<0,05)$. Oluşan bu farklılığın hangi ikili grup arasında oluştuğu ayrıca Mann Whitney-U yöntemi kullanılarak incelenmiştir. Sonuç olarak X kuşağının kaygı düzeylerinin $Y$ ve $Z$ kuşaklarına göre anlamlı derecede $(p<0,05)$ daha düşük olduğu tespit edilmiştir. Ayrıca $X$ ve $Y$ kuşaklarının kontrol düzeylerinin $Z$ kuşağının kontrol düzeyinden anlamlı derecede $(\mathrm{p}<0,05)$ yüksek olduğu tespit edilmiştir. Bu bağlamda H1 hipotezi kabul edilmişstir.

Tablo 6: Kariyer Uyum Yetenekleri Düzeylerinin Cinsiyete Göre Değişimi

\begin{tabular}{|c|c|c|c|c|c|}
\hline & & $\mathbf{N}$ & $\begin{array}{c}\text { Siralar } \\
\text { Ortalaması }\end{array}$ & $\begin{array}{c}\text { Mann- } \\
\text { Whitney U }\end{array}$ & $\mathbf{P}$ \\
\hline \multirow{2}{*}{ Güven } & Erkek & 258 & 303,19 & \multirow{2}{*}{44812,0} & \multirow{2}{*}{0,22} \\
\hline & Kadın & 368 & 320,73 & & \\
\hline \multirow{2}{*}{ Kontrol } & Erkek & 258 & 311,04 & \multirow{2}{*}{46836,5} & \multirow{2}{*}{0,77} \\
\hline & Kadın & 368 & 315,23 & & \\
\hline \multirow{2}{*}{ Merak } & Erkek & 258 & 312,26 & \multirow{2}{*}{47152,5} & \multirow{2}{*}{0,89} \\
\hline & Kadın & 368 & 314,37 & & \\
\hline \multirow{2}{*}{ Kayg1 } & Erkek & 258 & 300,74 & \multirow{2}{*}{44180,5} & \multirow{2}{*}{0,14} \\
\hline & Kadın & 368 & 322,44 & & \\
\hline \multirow{2}{*}{ Toplam } & Erkek & 258 & 304,40 & \multirow{2}{*}{45124,0} & \multirow{2}{*}{0,29} \\
\hline & Kadın & 368 & 319,88 & & \\
\hline
\end{tabular}

Kariyer uyum yetenekleri düzeylerinin cinsiyete göre anlamlı bir farklılık gösterip göstermediği Mann Whitney-U testi ile incelenmiştir. Buna göre ortalamalar arasındaki farklılık tüm alt boyutlar için anlamlı değildir $(\mathrm{p}>0,05)$. Bu bağlamda $H 2$ hipotezi reddedilmiştir. 
Tablo 7: Kariyer Uyum Yetenekleri Düzeylerinin Eğitim Durumuna Göre Değişimi

\begin{tabular}{|c|c|c|c|c|c|c|}
\hline & & $\mathbf{N}$ & $\begin{array}{c}\text { Siralar } \\
\text { Ortalaması }\end{array}$ & $k^{2}$ & $\mathbf{P}$ & Anlamlı Fark \\
\hline \multirow{4}{*}{ Güven } & Lise & 39 & 286,24 & \multirow{4}{*}{5,162} & \multirow{4}{*}{0,16} & \\
\hline & Önlisans & 171 & 325,99 & & & \\
\hline & Lisans & 284 & 300,19 & & & \\
\hline & Lisansüstü & 132 & 334,00 & & & \\
\hline \multirow{4}{*}{ Kontrol } & Lise & 39 & 349,09 & \multirow{4}{*}{6,358} & \multirow{4}{*}{0,10} & \\
\hline & Önlisans & 171 & 303,15 & & & \\
\hline & Lisans & 284 & 302,14 & & & \\
\hline & Lisansüstü & 132 & 340,83 & & & \\
\hline \multirow{4}{*}{ Merak } & Lise & 39 & 329,40 & \multirow{4}{*}{3,253} & \multirow{4}{*}{0,35} & \\
\hline & Önlisans & 171 & 293,30 & & & \\
\hline & Lisans & 284 & 317,65 & & & \\
\hline & Lisansüstü & 132 & 326,03 & & & \\
\hline \multirow{4}{*}{ Kayg1 } & Lise & 39 & 318,38 & \multirow{4}{*}{7,721} & \multirow{4}{*}{0,04} & Lisansüstü $>$ Lisans \\
\hline & Önlisans & 171 & 323,30 & & & \\
\hline & Lisans & 284 & 293,18 & & & \\
\hline & Lisansüstü & 132 & 343,08 & & & \\
\hline \multirow{4}{*}{ Toplam } & Lise & 39 & 327,47 & \multirow{4}{*}{6,526} & \multirow{4}{*}{0,09} & \\
\hline & Önlisans & 171 & 301,71 & & & \\
\hline & Lisans & 284 & 302,98 & & & \\
\hline & Lisansüstü & 132 & 347,28 & & & \\
\hline
\end{tabular}

Kariyer uyum yetenekleri düzeylerinin eğitim durumuna göre değişimi Kruskal Wallis yöntemi kullanılarak incelenmiştir. Buna göre kariyer uyum yetenekleri düzeyleri kaygı alt boyutu bağlamında eğitim durumuna göre anlamlı derecede $(\mathrm{p}<0,05)$ farklılık göstermektedir. $\mathrm{Bu}$ farklılığın hangi ikili grup arasında oluştuğu ayrıca Mann Whitney-U yöntemi kullanılarak incelenmiştir. Sonuç olarak kaygı alt boyutunda lisans ve lisansüstü eğitim düzeyleri arasında farklılık anlamlıdır $(\mathrm{p}<0,05)$. Lisansüstü grubunun kayg1 düzeyleri lisans grubuna göre daha yüksektir. Bu bağlamda $H 3$ hipotezi kabul edilmiştir.

Tablo 8: Kariyer Uyum Yetenekleri Düzeylerinin Mezuniyet Durumuna Göre Değişimi

\begin{tabular}{|c|c|c|c|c|c|}
\hline & & $\mathbf{N}$ & $\begin{array}{c}\text { Siralar } \\
\text { Ortalaması }\end{array}$ & $\begin{array}{c}\text { Mann- } \\
\text { Whitney U }\end{array}$ & $\mathbf{P}$ \\
\hline \multirow{2}{*}{ Güven } & Okuyor & 196 & 300,90 & \multirow{2}{*}{39669,50} & \multirow{2}{*}{0,23} \\
\hline & Mezun & 430 & 319,25 & & \\
\hline \multirow{2}{*}{ Kontrol } & Okuyor & 196 & 289,49 & \multirow{2}{*}{37435,00} & \multirow{2}{*}{$\mathbf{0 , 0 2}$} \\
\hline & Mezun & 430 & 324,44 & & \\
\hline \multirow{2}{*}{ Merak } & Okuyor & 196 & 283,29 & \multirow{2}{*}{36218,00} & \multirow{2}{*}{$\mathbf{0 , 0 0}$} \\
\hline & Mezun & 430 & 327,27 & & \\
\hline \multirow{2}{*}{ Kayg1 } & Okuyor & 196 & 337,58 & \multirow{2}{*}{37421,00} & \multirow{2}{*}{$\mathbf{0 , 0 2}$} \\
\hline & Mezun & 430 & 302,53 & & \\
\hline \multirow{2}{*}{ Toplam } & Okuyor & 196 & 295,94 & \multirow{2}{*}{38699,00} & \multirow{2}{*}{0,10} \\
\hline & Mezun & 430 & 321,50 & & \\
\hline
\end{tabular}

Kariyer uyum yetenekleri düzeylerinin öğrenciliği devam eden katılımcılar ile mezun olanlar arasındaki değişimi Mann Whitney-U yöntemi kullanılarak incelenmiş̧ir. Buna göre kontrol merak ve kaygı alt boyutlarında mezuniyet durumuna göre ortalamalar arasındaki farklılık 
anlamlıdır $(\mathrm{p}<0,05)$. Öğrenimine devam eden bireylerin kaygı düzeyleri mezunlara nazaran daha yüksektir. Mezunların ise merak ve kontrol düzeyleri öğrenimine devam edenlere göre daha yüksek düzeydedir. Bu bağlamda H4 hipotezi kabul edilmiştir.

Tablo 9: Kariyer Uyum Yetenekleri Düzeylerinin Çalışma Durumuna Göre Değişimi

\begin{tabular}{|c|c|c|c|c|c|}
\hline & & $\mathbf{N}$ & $\begin{array}{c}\text { Siralar } \\
\text { Ortalaması }\end{array}$ & $\begin{array}{c}\text { Mann- } \\
\text { Whitney U }\end{array}$ & $\mathbf{P}$ \\
\hline \multirow{2}{*}{ Güven } & Çalışmıyor & 215 & 302,22 & \multirow{2}{*}{41757,50} & \multirow{2}{*}{0,25} \\
\hline & Çalışıyor & 411 & 319,40 & & \\
\hline \multirow{2}{*}{ Kontrol } & Çalışmıyor & 215 & 299,64 & \multirow{2}{*}{41202,50} & \multirow{2}{*}{0,16} \\
\hline & Çalışıyor & 411 & 320,75 & & \\
\hline \multirow{2}{*}{ Merak } & Çalışmıyor & 215 & 300,33 & \multirow{2}{*}{41351,00} & \multirow{2}{*}{0,19} \\
\hline & Çalışıyor & 411 & 320,39 & & \\
\hline \multirow{2}{*}{ Kayg1 } & Çalışmıyor & 215 & 334,83 & \multirow{2}{*}{39597,00} & \multirow{2}{*}{$\mathbf{0 , 0 3}$} \\
\hline & Çalışıyor & 411 & 302,34 & & \\
\hline \multirow{2}{*}{ Toplam } & Çalışmıyor & 215 & 306,93 & \multirow{2}{*}{42769,00} & \multirow{2}{*}{0,51} \\
\hline & Çalışıyor & 411 & 316,94 & & \\
\hline
\end{tabular}

Kariyer uyum yetenekleri düzeylerinin çalışma durumuna göre değişimi Mann Whitney-U testi yöntemi kullanılarak incelenmiştir. Buna göre kariyer uyum yetenekleri kaygı alt boyutu düzeyleri çalışma durumuna göre anlamlı derecede $(\mathrm{p}<0,05)$ farklıdır. Bir işte çalışmayanların kaygı düzeyleri bir işte çalışanlara nazaran daha yüksek düzeydedir. Bu bağlamda H5 hipotezi kabul edilmiştir.

\section{Sonuç}

Türkiye'de kuşaklar üzerine yapılan çalışmaların genel olarak istenilen düzeyde olmadığını söylemek mümkündür. Özellikle yabancı kaynaklardaki çalışmaların öncelikle uygulamanın yapıldığı bölgenin/ülkenin kuşak özelliklerini keşfetmeye dayalı olduğu görülmektedir. Bireysel özelliklerin kişiden kişiye göre dahi değişebileceği göz önüne alındığında farklı gelişmişlik düzeyindeki toplumlardaki kuşak özelliklerinin de değişebileceği düşünülebilir. Farklı pek çok çalışmada kuşakların sınıflandırılmasında farklı tarih aralıklarının kullanılması bunu destekler niteliktedir. Tüm bu belirsizliğe rağmen kuşak özelliklerinin küresel düzeyde kabul gören bir sınıflama ile incelenmesinin hem bir ihtiyaç olduğu hem de bilimsel çalışmalar açısından faydalı olacağı söylenebilir.

Çalışmada ele alınan bir diğer unsur kariyer uyum yetenekleri kavramıdır. Kariyer, günümüz insanının sahip olması, üzerinde düşünmesi, seçim yapması ve bu seçiminde belli bir noktadan sonra devam etmesini de içeren önemli bir kavramdır. Kariyer uyum yetenekleri de bu noktada devreye girmektedir; değişen yaşam koşulları, iş olanakları ve firsatlar karşısında bireyin uyumlu olabilmesi onun kariyerini sürdürmesi için önemlidir. Bu durum bireylerin mevcut işinde devam ederken bir pozisyon değişikliğine sıcak bakmaları olabileceği gibi öğrenimi devam ederken veya kariyerinin başında farklı hedeflere yönelme veya karşısına çıkan bir firsat karşısında yön değiştirmesi de olabilir. Birey mevcut kariyer yolu içinde değişen şartlara uyum sağlayabilmelidir.

Araştırma konusu ile ilgili olarak alan yazın incelendiğinde kariyer uyum yetenekleri kavramının $\mathrm{X}, \mathrm{Y}$ ve $\mathrm{Z}$ kuşakları bağlamında ve Türkiye genelinde ele alındığı bir çalışmaya rastlanılmamıştır. Benzer çalışmalarda (Akgemci ve Kalfaoğlu, 2018; Kanbur ve Şen, 2017) X ve Y kuşaklarını ele alınmakta ve örneklem seçimleri daha dar bir alanı veya belirli bir meslek grubunu/sektörü kapsamaktadır. Bunlar haricinde bazı çalışmalar (Turak Kaplan, 2019) kariyer uyum yetenekleri kavramını nitel olarak ele alırken; bazıları ise (Acar ve Ulutaş, 2017; Gül vd., 2019; Karacan Özdemir ve Yerin Güneri, 2017; Tanrıverdi vd., 2019) farklı örgütsel değişkenler ile olan etkileşimini ele almaktadır. Genel olarak örnek verilen çalışmalarda Z kuşağının da mensubu 
olabilecek örneklem gruplarının (öğrenciler/yeni mezunlar gibi) tercih edildiği görülse de ilgili çalışmalarda kuşaklar arası karşılaştırma bulunmadığını söylemek mümkündür.

$\mathrm{Bu}$ çalışma, farklı kuşakların mensubu bireylerin olaylara bakış açılarının değişebileceği dolayısıyla eylemlerinin/alacakları kararların da farklı olabileceği düşüncesi üzerinden hareket etmekte ve bireylerin kariyer uyum yeteneklerinin bu doğrultuda farklılaşacağını vurgulamaktadır. Elde edilen bulgulara göre $\mathrm{Y}$ ve $\mathrm{Z}$ kuşağındaki bireylerin kaygı boyutu düzeylerinin X kuşağındaki bireylere nazaran daha yüksek olduğu tespit edilmiştir. Buradan hareket ile bireylerin yaş1 ilerledikçe kaygı düzeylerinin azaldığını söylemek mümkündür. Özellikle kariyer seçimleri konusunda belirli bir yaşın üzerindeki bireylerin artık kariyer tercihleri, iş ve ailedeki rolleri sabitlenmiş ve belirsizlikten arınmış olmaktadır. Ayrıca X kuşağının kanaatkâr özelliği ve otoriteye olan inanc1 çerçevesinde kaygı düzeyinin düşüklügünden söz edilebilir. Bununla birlikte kayg1, kariyer uyum yetenekleri çerçevesinde geleceğe duyulan kaygıyı ve ileride karşılaşılacak sorunlar için hazır olabilmeyi içermektedir. Dolayısı ile X kuşağında bu düzeylerin düşük çıkması olasıdır. Öte yandan $\mathrm{X}$ ve $\mathrm{Y}$ kuşaklarının kontrol düzeylerinin $\mathrm{Z}$ kuşağından yüksek olduğu tespit edilmiştir. Y kuşağı özelliği dâhilinde daha bireyci bir yapıya sahiptir. Dolayısı ile kendisi ile ilgili konularda kontrolü elinde bulundurmak isteyecektir. X kuşağı açısından kontrol düzeyinin görece fazlalığı kaygılı yapılarına, yüksek motivasyonlu oluşlarına veya toplumsal duyarlılıklarına bağlanabilir. $Z$ kuşağının ise daha çok işbirlikçi yapısı ön plana çıkmaktadır. Z kuşağı kendisi ile ilgili konular da dâhil olmak üzere pek çok konuda sorunların çözümünde veya bir şeyleri anlamlandırmada iş birliği içinde olmayı tercih edebilir. Bu durumun kontrol düzeylerinin $\mathrm{Z}$ kuşağında daha düşük tespit edilmesini açıkladığı düşünülmektedir.

Kadın ve erkekler arasında kariyer uyum yetenekleri düzeyleri anlamlı derecede bir farklılığa sahip değildir. Bu sonuç da oldukça anlamlıdır. Genel inanış cinsiyet arasındaki farklılıkların olduğu yönünde ise de yazında yer aldığı gibi bu düşünce aslen cinsiyet ayrımcıllğı ile ilgilidir (Alparslan vd., 2015; Dalgakıranoğlu ve Çetinel, 2008; Kocacık ve Gökkaya, 2005).

Eğitim düzeyi açısından bakıldığında lisansüstü derecesinde eğitime sahip olanların lisans derecesindekilere nazaran kaygı düzeylerinin daha yüksek olduğu tespit edilmiştir. Eğitim düzeyini bir seviye yukarıya ve daha ileriye taşımak isteyen bireylerin öncelikle mevcut durumlarını daha iyiye götürme konusunda diğer bireylerden daha fazla isteğe sahip oldukları düşünülmektedir. $\mathrm{Bu}$ bağlamda kişinin eğitim seviyesi ilerledikçe yine mevcut durumu sorgulaması neticesinde kayg1 düzeyinin diğer bireylere göre daha yüksek olmasının açıklanabilir olduğu düşünülmektedir. Mevcut eğitim düzeyini yeterli bulan ve daha fazlası için bir istek duymayan bireylerin hali hazırdaki durumundan da hoşnut olması muhtemeldir ve dolayısıyla elde edilen sonuçlar ile paralel olarak daha az kaygı duyması beklenmektedir.

Genel olarak mezun olan veya eğitimine devam eden bireylerin kariyer uyum yetenekleri düzeyleri incelendiğinde mezunların kaygı düzeylerinin daha düşük olduğu tespit edilmiştir. $\mathrm{Bu}$ bağlamda eğitimine devam eden bireylerde mesleki gelecekleri ile ilgili belirsizliğin daha fazla olmasının kaygı düzeylerini artırdığg düşünülmektedir. Öte yandan merak ve kontrol düzeyleri açısından ise mezun olanların merak ve kontrol düzeylerinin eğitimine devam edenlere nazaran daha yüksek olduğu tespit edilmiştir. Mezuniyet sonrasında bireyin iş deneyimi ile ilgili arayışları hız kazanmakta, birey çeşitli işlerde görev alarak nelerin üstesinden gelebileceği konusundaki merakını gidermekte ve bu doğrultuda kendine olan güveni de artmaktadır. Artan güven ile birlikte birey kontrolü ele alma ve hayatını yönlendirme isteğini de göreceli olarak daha fazla duymaktadır. Dolayısı ile mezun bireylerin merak ve kontrol düzeylerinde gözlemlenen artışın sebebi bu doğrultuda ilişkilendirilebilir.

Çalışmayanların kaygı düzeylerinin çalışanlara nazaran daha yüksek olduğu tespit edilmiştir. Hiç şüphesiz ki öncelikle bir işte çalışmıyor olmak, kişinin geleceği ile ilgili bir takım kaygılara kapılmasına neden olmaktadır. Özellikle yeni mezun bir birey henüz bir işte çalışmamış ise neleri yapıp yapamayacağını da bilememektedir. Çalışan birey ise iş yaşamında geçirdiği süre 
doğrultusunda farklı görevler altında çalışarak kendini daha iyi tanımakta ve alabileceği iş yükünü daha iyi tayin edebilmektedir. Buna göre de bir takım tercihlerde bulunmakta ve kendisi için en uygun rol/görevi seçme yoluna gidebilmektedir. Ortadan kalkan bu belirsizliğin çalışan bireyin kayg1 düzeyini görece olarak aşağıya çekebileceği düşünülmektedir.

Sonuç olarak Türkiye'de kuşaklar üzerine yapılan çalışmaların artması, konunun bireysel, kurumsal ve toplumsal öneminin farkına varılması bakımından fayda sağlayacaktır. Özellikle günümüz bilgi çağında ister bireysel düzeyde ister toplumsal düzeyde veya kurumsal düzeyde karar alırken işlenen verilerin değerlendirilmesi önemlidir. Kuşağa özgü özelliklerin farkında olarak kariyer tercihlerinin yapılması, işe alım konusunda doğru adayın seçilmesi ve yeni kuşakların bilinçli bir kariyer yolu izlemeleri öncelikle bu konunun doğru şekilde anlaşılması ile sağlanabilecektir.

\section{Kaynakça}

Abramson, P. R. ve Inglehart, R. (1992). Generational Replacement and Value Change in Eight West European Societies. British Journal of Political Science, 22 (2), 183-228, https://doi.org/10.1017/s0007123400006335

Acar, S. ve Ulutaş, A. (2017). Bilgisayar ve Öğretim Teknolojileri Eğitimi Bölümü Öğrencilerinin Kariyer Uyum Yeteneklerini Belirlemeye Yönelik Bir Araştırma. Journal of Human Sciences, 14(4), 4910-4925, https://doi.org/10.14687/jhs.v14i4.5022

Akgemci, T. ve Kalfaoglu, S. (2018). X Ve Y Kuşaklarının Kariyer Uyum Yetenek Düzeylerini Belirlemeye Yönelik Bir Araştırma: Lise Öğretmenleri Örneği. Nevşehir Hacı Bektaş Veli Üniversitesi SBE Dergisi, 8(2), 231-247, https://doi.org/10.30783/nevsosbilen.470434

Alparslan, A. M., Çetinkaya Bozkurt, Ö. ve Özgöz, A. (2015). İşletmelerdeCinsiyet Ayrımcılığı ve Kadın Çalışanların Sorunları. Mehmet Akif Ersoy Üniversitesi İktisadi ve İdari Bilimler Fakültesi Dergisi, 2(3), 6-81, https://doi.org/10.30798/makuiibf.295774

Aminul, I., Cheong, T. W., Yusuf, D. H. M. ve Desa, H. (2011). "A Study on Generation at Workplace in Penang." Journal of Applied Sciences Research, 7(11): 1802- 1805.

Arslan, A. ve Staub, S. (2015). Kuşak Teorisi ve İç Girişimcilik Üzerine Bir Araştırma. Kafkas Üniversitesi İ̈BF Dergisi, 6(11), 1-24, https://doi.org/10.18657/10.18657/yonveek.399459

Berkup, B.S. (2014). Working With Generations X And Y in Generation Z Period: Management of Different Generations in Business Life. Mediterranean Journal of Social Sciences, 5(19), 218-229, https://doi.org/10.5901/mjss.2014.v5n19p218

Broadbridge, A.M., Maxwell, G.A. ve Ogden, S.M. (2007). Experiences, Perceptions and Expectations of Retail Employment for Generation Y. Career Development International, 12(6), 523-544, https://doi.org/10.1108/13620430710822001

Coupland, D. (1989). The Young and Restless Work Force Following The Baby Boom: Generation X, St. Martin's Press.

Dalgakıranoğlu, T. ve Çetinel F.G. (2008). "Konaklama İşletmelerinde Kadın ve Erkek Yöneticilerin Cinsiyet Ayrımcılığına Karşı Tutumlarının Karşılaştırılması.” Dumlupınar Üniversitesi Sosyal Bilimler Dergisi, 20: 277-298.

Demirkaya, H., Akdemir, A., Karaman, E. ve Atan, Ö. (2015). Kuşakların Yönetim Politikası Beklentilerinin Araștırılması. İșletme Araștırmaları Dergisi, 7(1), 186-204, https://doi.org/10.20491/isader.2015115758 
Deneçli, C., Deneçli S. (2010). Nabza Göre Şerbet, Kuşağa Göre Etkinlik: Eğlencenin Pazarlanması, İstanbul Kültür Üniversitesi Sanat ve Tasarım Fakültesi İletişim Sanatları Bölümü, http://www.iku.edu.tr/userfiles/file/sanattasrim/doc/Ceyda_Denecli_Sevda_Denecli.doc, https://doi.org/10.3726/978-3-653-05967-0/14

Dündar, G. (2013). Kariyer Geliştirme, (içinde) Uyargil, C., Dal, Z.,Ataay, İ.D., Acar, A.C., Özçelik, O., Dündar, G., Sadullah, Ö. ve Tüzüner, L. İnsan Kaynakları Yönetimi, Beta Yayınları.

Ekşili, N., Ünal, Z. ve Batur, H.Z. (2014). "İş Yaşamında X Kuşağı Yöneticilerin Algılama Farkl111klarından Kaynaklanan Performans Değerlemeleri Üzerine Bir Araştırma." Uluslararası Ekonomi Kongresi, 3-5 Ekim 2014, Prag, Çek Cumhuriyeti.

Erdoğmuş Zorver, C. ve Korkut Owen, F. (2014). Kariyer Uyumu ve İyimserliği Ölçeği'nin geliştirilmesi. International Journal of Human Sciences, 11(2), 314-331, https://doi.org/10.14687/ijhs.v11i2.2911

Ertürk, M. (2011). İnsan Kaynakları Yönetimi, Beta Yayınları.

Gül, H., Maksüdünov A., Yamaltdinova, A. ve Abdildaev, M. (2019). Öğrencilerin Demografik Özelliklerinin Kariyer Uyumluluğu ve İyimserliği ile İlişkisi: Kırgızistan Örneği. KMÜ Sosyal ve Ekonomik Araştırmalar Dergisi, 21(36), 34-46, https://doi.org/10.29106/fesa.553242

Hicks, R. ve Hicks, K., (1999). Boomers, Xers, and other strangers: Understanding the generational differences that divide us, Tyndale House.

Howe, N., Strauss, W. (1991). Generations: The History of America's Future, 1584 to 2069, Morrow.

Howe, N. ve Strauss, W. (1992). “The New Generation Gap.” The Atlantic Monthly, 91(12): 6789.

Hutchings K. ve Michailova, S. (2014). Research Handbook on Women in International Management, (içinde) Moeller, M., Napier N. ve McGourty, R., Career and Family Expectations of Women in International Management: A View Across Generations, Cheltenham: Edward Elgar Publishing, https://doi.org/10.4337/9781781955031.00015

Kanbur E. ve Şen, S. (2017). X ve Y Kuşağ Çalışanlarının Kariyer Uyum Yetenekleri ve Kariyer Tatmini Açısından Karşılaştırılması. Journal of Turkish Studies. 12(12), 115-134, https://doi.org/10.7827/turkishstudies.12008

Kanten, S. (2012). Kariyer Uyum Yetenekleri Ölçeği: Geçerlilik ve Güvenilirlik Çalışması. SDÜ Sosyal Bilimler Enstitüsü Dergisi, 2(16), 191-205, https://doi.org/10.20875/sb.40564

Karacan Özemir, N. ve Yerin Güneri, O. (2017). The Factors Contribute to Career Adaptability of High-School Students. Eurasian Journal of Educational Research, 67, 183-198, https://doi.org/10.14689/ejer.2017.67.11

Keleş, H. N., (2011). "Y Kuşağı Çalışanlarının Motivasyon Profillerinin Belirlenmesine Yönelik Bir Araştırma." BAÜ Organizasyon ve Yönetim Bilimleri Dergisi, 3(2): 129-139.

Kocacık, F. ve Gökkaya, V.B. (2005). Türkiye'de Çalışan Kadınlar ve Sorunları. C.Ü. İktisadi ve İdari Bilimler Fakültesi Dergisi, 6(1), 195-219, https://doi.org/10.18657/yonveek.507622 
Konakay, G., Akdemir, A., Ergen, B., Solmaztürk, A. B., Gürer, A., Aktürk, F., Gökdemir, O., Yamaç, Ö., Sezen, S., Yavuz, S., Tın, U. (2015). Üniversite Öğrencilerinin Akademisyen ve Ebeveyn Etkileşimleri Işs̆ğında Liderlik Modeli Belirlenmesinde Karizma ve Entelektualite Etkisinin Araştırılması. İşletme Araştırmaları Dergisi, 7(1), 205-235, https://doi.org/10.20491/isader.2015115759

McCrindle, M. (2014). The A B C of X Y Z: Understanding the Global Generations, McCrindle Publication.

Noe, R. A. (2009). İnsan Kaynaklarının Eğitimi \& Geliştirilmesi (Çev: Canan ÇETİN), Beta Yayınlar1.

Parry, E. ve Urwin, P. (2010). Generational Differences in Work Values: A Review of Theory and Evidence. International Journal of Management Reviews, 13(1), 79-96, https://doi.org/10.1111/j.1468-2370.2010.00285.x

Savickas, M. L. (1994). Measuring Career Development: Current Status and Future Directions. The Career Development Quarterly, 10(43), 54-62, https://doi.org/10.1002/j.21610045.1994.tb00846.x

Savickas, M. L. (1997). Career Adaptability: An Integrative Construct for Life-Span, Life-Space Theory. The Career Development Quarterly, 45, 247-259, https://doi.org/10.1002/j.21610045.1997.tb00469.x

Savickas, M. L., Lota, L., Rossier, J., Dauwalder, J. P., Duarte, M.E., Guichard, J., Soresi, S., Esbroeck, R. V. ve Van Vianen, A.E.M. (2009). Life Designing: A Paradigm for Career Construction in the 21. Century. Journal of Vocational Behavior, 75(3), 239-250, https://doi.org/10.1016/j.jvb.2009.04.004

Savickas, M. L. ve Porfeli, E. J. (2012). Career Adapt-Abilities Scale: Construction, Reliability, and Measurement Equivalence Across 13 Countries. Journal of Vocational Behavior, 80(3), 661-673, https://doi.org/10.1016/j.jvb.2012.01.011

Senbir, H. (2004). Z Son İnsan Mi?, O Kitaplar.

Super, D. E. (1980). A life-span, life-space approach to career development. Journal of Vocational Behavior, 16, 282-298, https://doi.org/10.1016/0001-8791(80)90056-1

Super, D. E., ve Knasel, E. G. (1981). Career development in adulthood: Some theoretical problems and a possible solution. British Journal of Guidance \& Counselling, 9(2), 194201, https://doi.org/10.1080/03069888108258214

Tanrıverdi, H., Yılmaz, A., Pala, B. ve Ercan, F. Z. (2019). Kişilik Özellikleri, Duygusal Zekâ, Kariyer Uyum Yeteneği Ve Turizmde Kariyer Yapma İsteği Arasındaki İlişkilerin İncelenmesi: İstanbul Üniversitesinde Turizm İşletmeciliği Eğitimi Alan Öğrenciler Üzerine Bir Araştırma. Uluslararası Turizm, İşletme, Ekonomi Dergisi, 3(1), 41-56, https://doi.org/10.17719/jisr.20185639078

Taş, H. Y., Demirdöğmez, M. ve Küçükoğlu, M. (2017). Geleceğimiz Olan Z Kuşağının Çalışma Hayatına Muhtemel Etkileri. Opus Uluslararası Toplum Araştırmaları Dergisi, 7(13), 10301048, https://doi.org/10.26466/opus.370345

Taylor, J. C. (2008). "Whither March the Cohorts: he validity of Generation theory as a Determinant of the Socio Cultural Values of Canadian Forces Personnel." Canadian Forces College, 10(10):1-66.

TDK Sözlük (t.y.). Kuşak Kavramı, http://sozluk.gov.tr/, E.T.:22.06.2019. 
Turak Kaplan, B. (2019). İnsan Kaynaklarının Mücadele Ruhu: Kariyer Uyum Yetenekleri. Uluslararas1 Sosyal ve Beşeri Bilimler Araştırma Dergisi, 6(38), 1566-1572, https://doi.org/10.26450/jshsr.1257

Yazıcıoğlu, Y. ve Erdoğan, S. (2004). SPSS Uygulamalı Bilimsel Araştırma Yöntemleri, Detay Yayıncilik.

Yousefi Z., Abedi M., Baghban I., Eatemadi O. ve Abedi, A. (2011). Personal and Situational Variables, and Career Concerns: Predicting Career Adaptability in Young Adults. The Spanish Journal of Psychology, 14(1), 263-271, https://doi.org/10.5209/rev_sjop.2011.v14.n1.23

Zemke, R., Raines, C. ve Filipczak, B. (2013). Generations at Work: Managing the Clash of Boomers, Gen Xers, and Gen Yers in the Workplace, Amacom. 